\title{
Amniotic membrane a better graft and a dressing material for the root coverage?
}

\author{
Vanishree HS ${ }^{1}$, Vinesh Kamat ${ }^{2}$, Anand S Tegginamani ${ }^{3}$
}

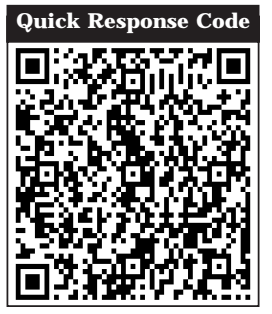

doi: $10.5866 / 2016.8 .10132$

${ }^{1}$ Faculty of Dentistry

SEGi University, Kota Damansara, Malaysia 47810

2Senior Lecturer,

Dept. of Periodontics

Coorg Institute of Dental Sciences

Virajpet 571218, Coorg, Karnataka.

${ }^{3}$ Faculty of Dentistry

SEGi University

Kota Damansara, Malaysia 47810

\section{Article Info:}

Received: April 11, 2016

Review Completed: May 10, 2016

Accepted: J une 11, 2016

Available Online: September, 2016 (www.nacd.in)

(C) NAD, 2016 - All rights reserved

\section{E mail for correspondence:}

vanipedo2010@rediffmail.com

\begin{abstract}
:
Gingival recession is defined as the apical migration of gingival margin to the cemento-enamel junction, gingival recession is relatively prevalent in the general population and may be associated with unfavorable esthetics, dentin hypersensitivity, and susceptibility to root caries, and diminished aesthetic/ cosmetic appeal, of thefactors contributing to gingival recession, trauma from tooth brushing is the most common other factors include anatomic variations smoking, oral habits, mal positioning and orthodontic tooth movement. Guided tissue regeneration (GTR) based root coverage has emerged as a promising treatment modality. A variety of non-resorbable and bioresorbable membranes have been successfully used. Among resorbable membranes, collagen has been extensively studied. Recently, amnion membrane, the third generation membrane which is a placental derived tissue has been introduced and been utilized to correct gingival recession defects with promising results. Amnion and chorion allograft membranes of alternative origin derived from human placental tissue has been advocated in the treatment of gingival recession. Here in this report we present a case of gingival recession treated with guided tissue regeneration (GTR) principle using amnion placental membrane.
\end{abstract}

Key words: aesthetics, allograft, amnion membrane, gingival recession, root coverage, gingival defects, periodontal surgery.

\section{Introduction:}

The main objective of any therapeutic intervention aimed at root coverage is to restore the tissue margin to the cemento-enamel junction and to gain an attachment of the tissue to the root surface such that the gingival sulcus showing no bleeding on probing and a minimal probing depth. Mesenchymal stem cells (MSCs) are one of the major cells population that play an important role in mediating each phase of the wound heal ing process: Inflammatory, proliferative, and remodeling. Recently, the fetal derived MSCs from the placenta or other gestational tissues like the amniotic fluid, umbilical cord are novel materials with rich stem cell reserves. The use of placental tissue for the treatment of wound started for more than 100 years ago when Davis in 1910 first used these fetal membranes as skin substitutes for the treatment of open wounds. ${ }^{1,2}$ 
Recently, the use of allografts has been suggested for root surface coverage as an alternative to autogenous grafts. One of these products is acellular dermal matrix allograft (ADMA), which has been recommended as an alternative to autogenous grafts to cover denuded roots to prevent the need to harvest a connective tissue graft (CTG). However, subsequent studies of the amount of root coverage and esthetic results have yiel ded different findings, and insufficient data are available about long-term outcomes of the procedure. Recently, a new allograft was introduced; it is derived from amniotic membrane (AM) and can decrease inflammation and scar formation to promote wound healing by encouraging cellular proliferation and differentiation. In addition, it has antimicrobial properties and inhibits bacterial infection by inducing a rapid physiologic seal and promoting wound healing, as it also contains growth factors. Amniotic membrane is easily obtained and has been used in ophthalmologic surgeries, skin grafts, and treatment of burns and wounds. It was initially used as a surgical material in skin transplantation and for the treatment of burned or wounded skin. Later, AM was used for the treatment of scleral lesions revived its use in ophthalmologic surgery. Many studies have confirmed the antimicrobial and antiinflammatory properties and efficacy of AM. The antimicrobial and anti-inflammatory properties of $\mathrm{AM}$, along with the similarity between the basement membranes of AM and the oral mucosa, might make it a suitable alternative to a CTG. Amniotic membrane strongly resembles the oral mucosa basement membrane and contains different types of laminins, especially laminin-5, which plays an important role in the adhesion of gingival cells, laminins can promote regeneration, accel eratetissue adhesion, and preserve tissues, all of which are key factors in improved healing of gingival lesions and might result in clinical attachment level (CAL) and probing depth (PD) improvements. F urthermore, the antimicrobial agents that are present in AM, especially secretory leukocyte proteinase inhibitor I, lactoferrin, defensin, and elafin, might improve wound healing, especially in patients with poor oral hygiene. $^{2}$
In the field of periodontics, recently Velez and co-workers analyzed the effects of the cryopreserved amniotic membrane on periodontal soft tissue healing and observed that it was effective in hel ping cicatrization, wound healing, epithelization, facilitated migration, and reinforced adhesionin. Here in this report we present a case of gingival recession treated with guided tissue regeneration (GTR) principle using amnion placental membrane. ${ }^{3,}$

\section{CASE REPORT:}

A 28-year-old male patient reported with a chief complaint of tooth hypersensitivity in the upper left back tooth region since 3 months. His medical and family history was non-contributory. On clinical examination, a Millers Class I gingival recession was observed in relation to the tooth number 23 measuring $3 \mathrm{~mm}$ vertically and horizontally (Figure 1). The patient had a thin gingival biotype. The treatment plan consisted of placement of an amnion membrane (Tissue bank, Tata Memorial Hospital, India) in conjunction with a coronally advanced flap.

The patient was given oral hygiene instructions and supragingival scaling and root planning was performed. After obtaining adequate anaesthesia using Lignocaine hydrochloride $2 \%$, two oblique beveled incisions, one on the mesial aspect and the other on the distal aspect of the recession site, to raise a trapezoidal flap followed by two vertical incisions extending into the alveolar mucosa were given. A trapezoidal flap was elevated, following which the exposed root surface was thoroughly planed. After the flap was raised, the recession width and height were measured using a UNC-15 probe and the membrane size was calculated as $2 \mathrm{~mm}$ more on all sides (apically, mesially and distally) to be of sufficient dimension to cover the recession. The membrane was then placed over the root surface (Figure 2) and the flap was sutured back in position with 4-0 resorbable vicryl sutures. Keeping in mind the adhesive properties of the amnion, the membrane was not sutured. Postoperative instructions, a combination of Dicl ofenac sodium (50 $\mathrm{mg}$ ) Paracetamol $325 \mathrm{mg}$ twice daily for 3 days, amoxicillin $500 \mathrm{mg}$ thrice for 5 days and a 


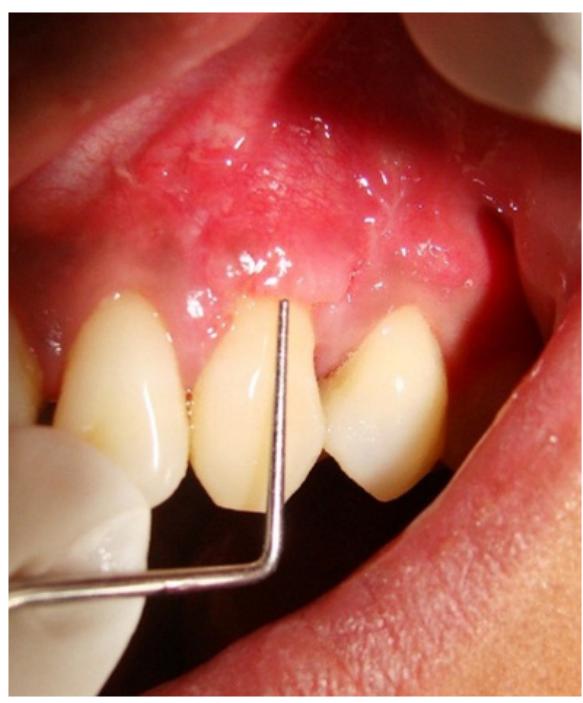

Figure 1: Intra oral examination reveal a Millers Class | gingival recession in relation to the tooth number 23 measuring about $3 \mathrm{~mm}$ vertically and horizontally.

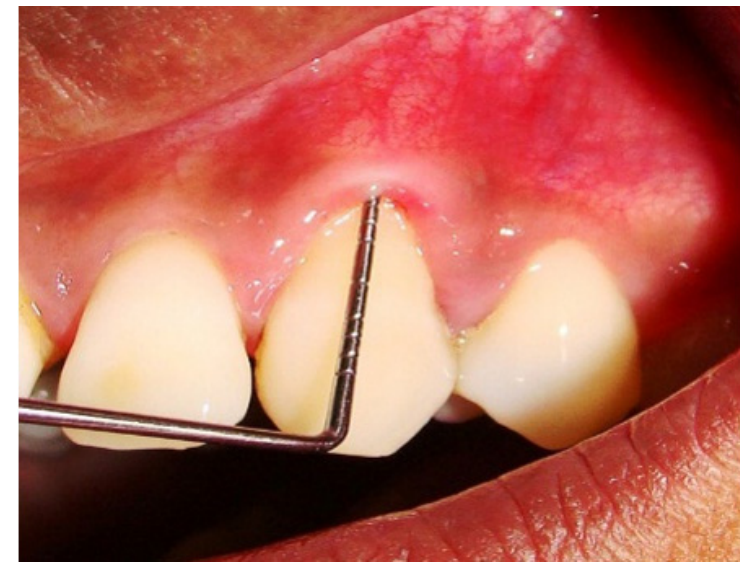

Figure 3: Post operative follow-up picture of the patient after 7 days.

Chlorhexidine mouth rinse $0.2 \%$ twice daily for 2 weeks were prescribed to the patient.

The patient was recalled after 7 days (Figure 3) and was followed-up till 9 months (Figure 4). Complete root coverage, with excellent tissue contour and colour blend, was observed over the period of follow-up.

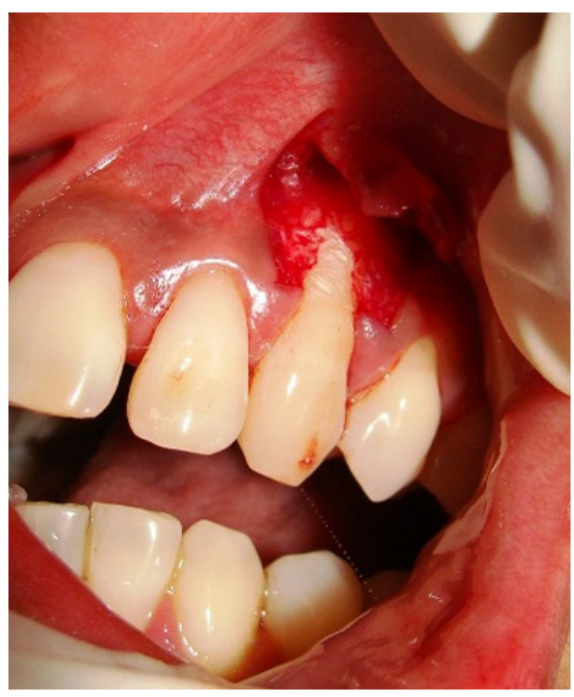

Figure 2: Placement of membrane over the root surface.

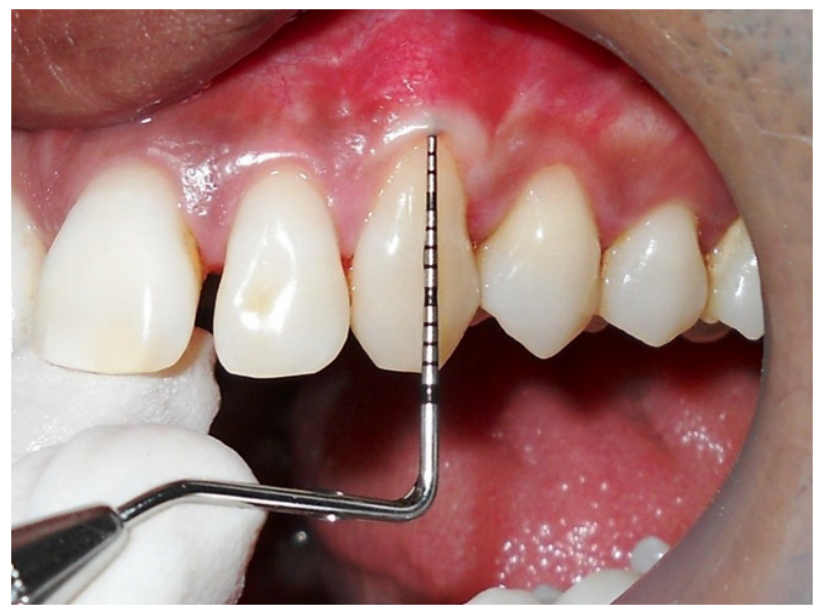

Figure 4: Post operative follow-up picture of the patient after 9 months.

\section{Discussion:}

Gingival recession is relatively prevalent in the general population and may be associated with unfavorable esthetics, dentin hypersensitivity, and susceptibility to root caries of the factors contributing to gingival recession, trauma from tooth brushing is the most common other factors include 
anatomic variations smoking, oral habits, malpositioning and orthodontic tooth movement.

The potential advantage of GTR to a gingival flap procedure is the possibility of having a different healing pattern and ideally achieving periodontal regeneration rather than connective tissue repair of the exposed root surfaces with no additional donor site. Recently, an allograft of alternative origin derived from human amnion tissue, is the innermost lining portion of the placental membrane has been advocated in the treatment of gingival recession. Amniotic membrane is a composite membrane consisting of pluripotent cellular element embedded in a semi permeable, membranous and is an immunotolerant structure. Also, there is existence of pluripotent stem cells possessing the ability of trans-differentiation to other cellular elements of periodontium making it a suitable candidate for GTR. Excellent revascularization of the amniotic membrane is another favorable property of this natural structure. It also contains growth factors that may aid in the formation of granulation tissue by stimulating fibroblast growth and neovascularization. Amnion has shown an ability to form an early physiologic "seal" with the host tissue precluding bacterial contamination and multiplestudies support amnion's ability to decrease the host immunologic response via mechanisms such as localized suppression of polymorphonuclear cell migration.Data suggests that the amnion basement membrane closely mimics the basement membrane of human oral mucosa. ${ }^{2,5-11}$

Amnion membrane is an allograft with many unique properties that make it a promising new substitute in the field of periodontics. It contains a variety of specialized proteins such as fibronectin, laminin, proteoglycans, glycosaminoglycan's and collagen type IV, V and VII. It not only provides a matrix for cellular migration and proliferation but also enhances the wound healing process. ${ }^{10} \mathrm{It}$ contains a large number of cytokines including transforming growth factor $\beta / \alpha$ vascular endothelial growth factor, epidermal growth factor, plateletderived growth factor $\beta / \alpha$ and fibroblast growth factor. It has been reported to be non-immunogenic, to reduce inflammation, reduces scar tissue, has antibacterial properties, reduces pain at the site of application and acts as a natural biological barrier. Such wound modulating properties make it an interesting new option for application in oral wound healing. Complete and stable root coverage is the ultimate goal of any root coverage procedure. In the present case, we observed that amnion allograft resulted in an excellent root coverage and color match to the recipient site. Amnion derived cells with multipotent differentiation ability have attracted lot of attention in the regeneration of periodontal tissues. Comparison of the efficacy of amnion allograft with connective tissue graft has shown that amnion allograft might be a suitable alternativeto connectivetissuegraft and can reduce recession depth in covering denuded root surfaces. Studies evaluating the effect of growth factors on root coverage have shown that these agents can decrease postoperative hemorrhage and desquamation and promote tissue regeneration and revascularization. Autogenous graft tissue procurement significant increases patient morbidity while also lengthening the duration of surgery in placing the graft, while self adhere nature of amniotic membrane significantly reduces surgical time and made the procedure easier to perform, making it membrane of choice. Despitetheseclinical outcomes, the use of autograft tissue has drawbacks. Autogenous graft tissue is limited in supply, and its procurement significantly increases patient morbidity while also lengthening the duration of surgery. 2, 5, 12

The results of the present case was stable for 9 months post treatment and no recurrence of the recession was observed, hence, all the optimum desired results were satisfactory as an allograft for root coverage were achieved by amnion allograft.

\section{CONCLUSION}

The present case report presents a novel material amnion allograft, its inherent wound modulating properties may be used to enhance periodontal wound healing and enable gingival tissue regeneration. Amnion allograft may provide an alternative to other conventional methods of treating gingival recession. The results from the present report are encouraging and demonstrate that the amnion allograft is well tolerated by the 
gingival tissues and results in excellent healing. Morestudies exploring the potential of this allograft in periodontal therapies are required. However randomised control trials with longer follow-up period need to be carried out to assess the long term benefits of amnion and chorion allografts.

\section{References}

1. Sharma A, Yadav K. Amniotic membrane A Novel material for the root coverage: A case series. J Indian Soc Periodontol 2015; 19 (4): 444-448.

2. Ghahroudi et al. Comparison of Amnion Allograft with Connective Tissue Graft for Root Coverage Procedures: A Double-Blind, Randomized, Controlled Clinical Trial. J Int Acad Periodontol 2013; 15(3):7-15.

3. Velez I, Parker WB, Siegel MA, Hernandez $M$. Cryopreserved amniotic membrane for modulation of periodontal soft tissuehealing: A pilot study. J Periodontol 2010; 8:1797-1804.

4. Mahajan R, Khinda PK, Shewale A, Saravanan SP. Guided Tissue Regeneration Based Treatment of Root Coverage using Placental Membrane Allograft: A Case Report. IJ SS Case Reports \& Reviews 2015; 2(7):1-5.

5. Chakraborthy S, Sambashivaiah S, Kulal R, Bilchodmath S. Amnion and Chorion Allografts in Combination with Coronally Advanced Flap in the Treatment of Gingival
Recession: A Clinical Study. J Clin Diagn Res. 2015; 9(9):98101

6. Niknejad H, Peirovi H, J orjani M, Ahmadiani A, Ghanavi J, Seifalian AM. Properties of the amniotic membrane for potential use in tissue engineering. Eur Cell Mater 2008; 15:88-99.

7. Velez I, Parker WB, Siegel MA, Hernandez $M$. Cryopreserved amniotic membrane for modulation of periodontal soft tissuehealing: A pilot study. J Periodontol 2010; 8:1797-1804

8. Brian G. A novel dehydrated amnion allograft for use in the treatment of gingival recession: An observational case series. J Imp Adv Cli Dent 2009; 1:11-16.

9. Miller PD J r. A classification of marginal tissue recession. Int J Periodontics Restorative Dent 1985; 5:8-13.

10. Kan J Y, Morimoto T, Rungcharassaeng K, Roe P, Smith $\mathrm{DH}$. Gingival biotype assessment in the esthetic zone: Visual versus direct measurement. Int J Periodontics Restorative Dent 2010; 30:237-243.

11. Larjava H, Wiebe C, Gallant-Behm C, Hart DA, Heino J Häkkinen L. Exploring scarless healing of oral soft tissues. J Can Dent Assoc 2011; 77:18.

12. Fetterolf DE, Snyder RJ . Scientific and clinical support for the use of a dehydrated amniotic membrane in wound management. Wounds 2012; 24:299-307.

\section{Gain quick access to our journal online View our journal at www.nacd.in}

